\title{
The Effects of Poverty on Childhood Development
}

\section{Jamie B. Royce}

Department of Behavioral Sciences, Eastern Florida State College, United States.

Article Details
Article Type: Mini Review
Received date: $08^{\text {th }}$ January, 2021
Accepted date: $17^{\text {th }}$ February, 2021
Published date: $19^{\text {th }}$ February, 2021

"Corresponding Author: Jamie B. Royce, Department of Behavioral Sciences, Eastern Florida State College, United States. United States. E-mail: jamiecampbell108@gmail.com

Citation: Royce, J.B. (2021). The Effects of Poverty on Childhood Development. J Ment Health Soc Behav 3(1):132. https:// doi.org/10.33790/jmhsb110032

Copyright: $\mathbb{C}_{2021}$, This is an open-access article distributed under the terms of the Creative Commons Attribution License 4.0, which permits unrestricted use, distribution, and reproduction in any medium, provided the original author and source are credited.

\begin{abstract}
There is no denying that the effects of poverty are vast and farreaching. From life expectancy to academic success, the effects it has have inundated many aspects of life for those who identify with the socioeconomic status. Those who are largely effected by it are some of society's most vulnerable individuals children. Children living in poverty often lack easy access to proper housing, education, nutrition, and medical care. In both developed and non-developed countries, poverty is continuously linked to deficits in biological, cognitive, emotional, and academic development.
\end{abstract}

This paper aims to explore the many different effects poverty and its associated domains have on childhood development. From infancy through adolescence and the ripple effect it has on adulthood, the consequences of living in low-income environments will be discussed in relation to proper childhood development. Due to the malleable nature of the brain during these crucial formative years, many of the issues faced during childhood can persist into adolescence and further into adulthood. For these reasons, the long lasting effects of enduring poverty into adulthood will also be examined.

Keywords: Childhood poverty, Infancy, Toddlerhood, Adolescence, Development

\section{Fetal Development and Infancy}

Many of the problems children born into poverty face begin before they are even born. Poor prenatal care is positively associated with poverty. Women living in poverty are less likely to have been vaccinated for infectious diseases that can be passed on to the fetus. Diseases like Rubella, which are easily treated by inoculation, can be extremely harmful to a growing fetus [1]. Expectant mothers living in poverty also experience higher levels of stress, which can flood the body and brain of the fetus with potentially toxic levels of stress hormones [2]. Many of these expectant mothers living in poverty are adolescents. Due to the relative immaturity of teenage mothers, they are less likely to receive proper prenatal care or follow nutrient-rich diets that are integral to healthy fetal development. They are also more likely to partake in drug and/or alcohol use and abuse than nonpoor pregnant women.

These activities often lead to premature births, low birth weights, newborn health problems, and developmental disabilities, all of which can be particularly harmful to proper newborn development [3]. Babies born prematurely are often underweight and face significant health problems [4]. Low birth weights and premature birth also increases the baby's risk of dying in the first weeks and months of life [3]. Less fatal repercussions of premature birth include increased behavioral problems and learning disabilities later in life.
Premature birth is also associated with an increased risk of mental health disorders and physical disabilities. Children born with physical and developmental disabilities can be particularly challenging for young mothers who lack social, emotional, or financial support [3]. This can result in improper care and stimulation for the child.

Conditions of poverty can be especially harmful during infancy, when proper nurturance and health care are most important. In the earliest years of life, a safe and healthy environment are integral for optimal cognitive development. It is for these reasons that infants are especially susceptible to conditions of poverty. Substandard living conditions can often be toxic and harmful to infants, leaving long lasting effects their wake.

Poverty is typically associated with circumstances such as poor nutrition, food insecurity, inadequate physical and mental health care, limited parental education, lack of stimulating parent/child interactions, harsh punishments, and child abuse and neglect [5]. During infancy, brain growth and development occurs so rapidly that an occurrence in any of the aforementioned domains can have abiding adverse effects. Other poverty related hazards such as poor nutrition, vitamin $\mathrm{D}$ and iron deficiency, and exposure to toxins like lead can take a permanent toll on brain growth. Coupled with environmental stressors like harsh or neglectful parenting and inadequate stimulation, these factors can cause significant disruption in the infant's executive control functions, memory, attention, reactivity to stress, and ability to regulate anxiety [6]. Much like that of considerable prenatal stress, living conditions that cause significant stress to the parent also cause stress to the infant. These interdependent stress levels have been associated with difficulties in inhibitory control and attention-regulation among infants [7].

High levels of stress are also positively associated with living in poverty. Stress may not seem as hazardous as a condition like malnutrition, but to the developing brain of an infant it is severe. High levels of stress trigger the release of "stress hormones" like cortisol or adrenaline. In a fully-grown adult, these hormones may cause heart pounding and heightened pules rates. In an infant, these hormones can condition the brain to have a heightened response to stress and leave life-long after effects [8].

High levels of cortisol and adrenaline can be toxic to the mind and body of an infant. Chronic stressors associated with living in lowincome conditions, such as exposure to domestic violence, parental substance abuse, and living in high crime areas can all trigger the release of high levels of stress hormones. Constant release of these hormones results in elevated heart rate and blood pressure and can cause overdose levels of cortisol release that can be damaging to the developing brain and organ systems of an infant [2]. The constant 
presence of high levels of cortisol in the brain is also linked to anxiety disorders, heart disease, obesity, and other serious illnesses [9]. Many of these harmful effects can typically be buffered by the support of healthy family networks, which many children in poverty lack.

Infants living in conditions of poverty also face risk factors in their own family network. Maternal depression, maternal drug and/or alcohol abuse, and family violence are more common among low-income households [10]. Maternal depression is also much more common among single mothers living in poverty than for mothers in general [11]. Being cared for by a depressed mother can have harmful effects on the developing brain of an infant. Consistent positive interactions are integral to the proper development of newborns and infants, which depressed mothers may not be able to provide. Studies have also shown that maternal depression, especially when severe and chronic, is linked to behavioral problems and a greater risk of the child developing depression as they age [12]. These risk factors are once again heightened in households that lack father-figures or other affectionate adults to assist in child rearing [13]. Predictably, many of these adversities carry on into toddlerhood.

\section{Toddlerhood and Early Childhood}

Many of the poverty related hardships faced during infancy persist on into toddlerhood. As of 2007, it is estimated that over 200 million children under the age of five are exposed to poverty, malnutrition, and neglect, worldwide [14]. These conditions are also accompanied by chaotic stress-inducing living conditions, living in high-risk neighborhoods, exposure to violence, family instability, and disruptions in basic services such as water and electricity [15]. Coupled with a lack of adequate health care and educational resources, it should come as no surprise that enduring poverty during toddlerhood is extremely detrimental to development.

Lack of adequate health care can lead to repeated bouts of illness among toddlers. Children, in general, are more susceptible to poverty-related diseases due to their relatively immature immune systems [16]. It is rather common for children living in poverty to have no regular source of health care. Without routine health care visits, many of these children go without regular vaccinations for measles and other infectious diseases [17]. Other medical problems such as respiratory infections and diarrheal diseases are also common among toddlers. With medical treatment, these issues are typically only uncomfortable and inconvenient. However, when combined with poor nutrition, lack of consistent medical treatment, and poor sanitation, these minor health problems can become serious threats. The result of malnutrition and toddlerhood illnesses can include structural brain damage, lethargy, delayed physical growth, and minimal exploration of their environment [18]. Although diseases such as pneumonia and diarrhea are easily treated

with routine medical care, they still remain the most common cause of preventable deaths among children [16].

Life threatening illnesses are not the only health problems that children of meager resources face. Growing up in poverty sets many children on a trajectory for poor health. Low income and socioeconomic status are positively associated with elevated levels of blood pressure among children [19]. Other health related physical detriments encountered by children living in low-income areas include substandard housing, pollutant exposure, toxin exposure, sensory-overloading noise, and over crowding [20]. All of these factors can have a compelling negative effect on childhood health. Children living in low-income areas often inhabit unsafe and under resourced neighborhoods that provide little to no opportunities for recreation. This results in less exercise and an increased risk for childhood obesity [8]. Lack of exercise also results in a poor probability of inhibiting many of the aforementioned health risks.
Physical factors are not the only cause of hindered development in childhood. Many children living in low-income areas also lag behind on early learning tasks. Speech development and processing are particularly affected by conditions of poverty. Studies have shown that children of low parental income households are spoken to approximately four times less than their higher-income peers [21]. These conversations are also comprised of two and half times fewer words [21]. As children gain a large majority of their early learning skills from parents and caregivers, these insufficient exchanges inhibit early speech and vocabulary development. Many of these children enter preschool at a disadvantage. Early language skills have often been used as a marker for early academic achievement in preschool and elementary school. Low-income children typically enter school with not only a shorter vocabulary, but also underdeveloped social, emotional, and cognitive skills that underlie formal education. These children also tend to fall behind in school readiness and preparedness [8].

Even when parents are able to enroll children in early learning programs, the disadvantages often persist. The ratio of children to teachers are typically much higher in low-income communities. This means less personal engagement and one-on-one assistance for children enrolled in these programs [22]. Teachers and caregivers in low-income areas are also less likely to engage children in ways that are cognitively and educationally stimulating. Studies have found that educators in poorer child-care centers are generally less sensitive, less likely to respond to the children's needs, and more harsh to the children than those in higher-income areas [23]. This can be especially harmful to children who already face harsh or neglectful home environments.

Other poverty-related risk factors also affect school readiness and scholastic achievement among school-aged children. Poor development of executive functioning skills are one aspect of this unpreparedness. Executive functioning skills can be defined as the particular set of abilities involved in the coordination and control of information in goal-directed behavior [24]. These skills enable coordinated decision-making that is integral to socioemotional and cognitive competence [25]. These competencies play a large part in school preparedness. Many low-income children show vast differences in their executive functioning skills, compared to their higher-income peers.

These skills are increasingly important for planning, reasoning, and integrating thoughts and behaviors, especially for young children. Executive functioning skills also play a role in conflict resolution, reconciling information, and the functions of working memory. Considering early life experience and family environment can greatly influence neurocognitive development; it should be expected that executive functioning skills would also be effected. Many of the aforementioned stressors and risk factors, such as fetal drug exposure and poor stimulation in infancy, stand to easily inhibit the emergence of executive functioning skills [26]. This road-block to academic achievement and success continues on in to later childhood and adolescence.

\section{Adolescence and Beyond}

Adolescence is a time of great cognitive and physical change for any individual. For those living in poverty, it can be even more challenging. For many children who grew up in poverty, some of these physical and cognitive facilities have already been inhibited in early childhood. Challenges associated with puberty and entry in to adolescence may be exacerbated by conditions of poverty. Insufficient family resources, services, and experiences are among these challenges [27]. Environmental factors associated with lowincome neighborhoods, such as exposure to drug trafficking, gang violence, and prostitution, provide little to no opportunities for adolescents to develop positive social networks. Coupled with poor 
role modeling, these hazardous circumstances can foster very unhealthy developmental outcomes [27]. Due to these limited opportunities for positive social engagement, many adolescents living in poor neighborhoods are often socialized by older peers partaking in risk engagement activities that typically result in arrest and gun violence [27].

Following the trends of low-income childcare centers in toddlerhood, educational institutions in poor neighborhoods also fall behind. Schools in poor communities generally lack the resources to provide a quality education. Evidence of this is clear in the uptick of low student achievement, high school dropout rate, and school failure rates among low-income youths [28]. Subpar sex education in these institutions, combined with poor parenting, also contributes to higher rates of HIV/AIDS infection, teenage pregnancy, and early parenthood for many of these kids [29]. Unsurprisingly, sexual risk factors and teenage pregnancies are among the greatest detriments to young girls living in poverty.

Poverty is one of the leading predictors of teenage pregnancy. Other predictors of teenage pregnancy include low parental education, having low grades, living in a single-parent or stepparent household, and being sexually active [30]. All the aforementioned predictors are highly associated with conditions of poverty. Studies have also shown that living in low-resource households, in addition to high levels of distress, predicted an even higher risk for teenage pregnancy [17]. For many teenage mothers, early entry into parenthood, combined with low education level and limited resources, further perpetuates the cycle of poverty. For many of these young mothers, the disruption in normal teenage life that is brought about by childrearing puts them at an increased risk for depression.

Nonnormative life events that are increased in conditions of poverty, such as teenage pregnancy and dropping out of school, are positively associated with high levels of depression [31]. Median household income and ethnic composition are the greatest predictors of adolescent depression, over and above individual character traits. Unsurprisingly, living in a low-income household is positively associated with adolescent depression [32]. The effects of neighborhood poverty, such as low employability and early exposure to drugs and violence, can foster a sense of hopelessness that may account for these high levels of depression. Other factors like increased levels of daily stress, elevated vulnerability to negative events, and disruption of social ties also contributes to depression among poor youths [33]. The effects of low-income on depression were also heightened among adolescents whose parents had lower levels of education [34]. Many of these mental and physical effects of living in poverty continue to persist on into adulthood.

\section{Conclusion}

This persistence of poverty across the lifespan can often lead to a cycle of poverty. The cycle of poverty refers to the likelihood that a child who is raised in poverty will typically grow in to an adult who subsequently raises their children in poverty. For example, a teenage mother may drop out of school in order to raise her child. Rising childcare costs and an inability to work full time due to time constraints might force her into living in low-income areas. The child, having been exposed to conditions of poverty like low parental education and living in high-risk neighborhoods, now faces many of the same challenges that would cause them to make similar life choices. Although this cycle may be hard to break, suffering in conditions of poverty is not inevitable.

Poverty by itself is not a detriment to proper childhood development. Low household income may be a predictor of developmental difficulties, but it is not proof of it. The conditions that are associated with poverty, rather, stand to inhibit healthy physical and cognitive development. Poverty related risk factors, such as fetal exposure to drugs or alcohol, harsh and neglectful parenting, or inadequate health care are much more likely to leave long lasting negative effects than poverty in and of itself. Although children living in poverty face more hardships than their high income peers, they are not necessarily destined to fail. When healthy family environments, positive attitudes toward education, and proper socioemotional support buffer meager family resources they may not only flourish, but often achieve greatness [35].

Conflict of interests: The authors declare no conflict of interest.

\section{References}

1. Burgard, S.A. \& King, M.M. (2015). Health. Pathways: A Magazine on Poverty, Inequality, and Social Policy, Special Issue, State of the States, 2015.

2. Shonkoff, J. P., Garner, A. S., Siegel, B. S., Dobbins, M. I., Earls, M. F., Garner, A. S., McGuinn, L., ... Wood, D. L. (2012). The Lifelong Effects of Early Childhood Adversity and Toxic Stress. Pediatrics, 129, 1.)

3. Brooks-Gunn, J., \&Duncan, G. J. (1997). The Effects of Poverty on Children. Future of Children, 7, 2, 55-71.

4. Goldenberg, R. L., \& Culhane, J. F. (2007). Low birth weight in the United States. American Journal of Clinical Nutrition, 85.

5. Yoshikawa, H., Aber, J. L.,\&Beardslee, W. R. (2012). The effects of poverty on the mental, emotional, and behavioral health of children and youth: implications for prevention. The American Psychologist, 67, 4.

6. Rodier, P. (2004). Environmental causes of central nervous system maldevelopment. Pediatrics, 113, 1076-1083.

7. Lempinen, E.W. (2012). AAAS Briefing:Links between poverty, brain development raise kep policy issues. AAAS News Release. Retrieved from http://www.aaas.org//news/ releases/2012/0731 early_brain.shtml

8. Azzi-Lessing,L.,\&Schor,L.B.(2017).Behindfrom thestart:How America's waron the poor is harming ourmost vulnerable children.

9. McEwen, B. S. (2007). Physiology and neurobiology of stress and adaptation: central role of the brain. Physiological Reviews, 87, 3, 873-904.

10. Carter, A. S., Garrity-Rokous, F. E., Chazan-Cohen, R., Little, C., \& Briggs-Gowan, M. J. (2001). Maternal Depression and Comorbidity: Predicting Early Parenting, Attachment Security, and Toddler Social-Emotional Problems and Competencies. Journal-American Academy of Child and Adolescent Psychiatry, 40, 18-26.

11. Knitzer, J., Theberge, S., Johnson, K., \& Columbia University. (2008). Reducing maternal depression and its impact on young children: Toward a responsive early childhood policy framework. New York, NY: Columbia University, Mailman School of Public Health.

12. Goodman, S. H., Rouse, M. H., Connell, A. M., Broth, M. R., Hall, C. M., \& Heyward, D. (2011). Maternal Depression and Child Psychopathology: A Meta-Analytic Review. Clinical Child and Family Psychology Review, 14, 1, 1-27.

13. Thompson, R., \& Wiley, T. (2009). Predictors of Re-Referral to Child Protective Services. Child Maltreatment, 14, 1, 89-99.

14. Grantham-McGregor, S., Cheung, Y. B., Cueto, S., Glewwe, P., Richter, L., Strupp, B., \& International Child Development Steering Group. (2007). Developmental potential in the first 5 years for children in developing countries. Lancet (london, England), 369, 9555, 60-70.

15. Ceballo, R., \&McLoyd, V. C. (2002). Social Support and Parenting in Poor, Dangerous Neighborhoods. Child Development, 73, 4, 1310-21.

16. Adams, L. V., Butterly, J. R., \& University Press of New England. (2015). Diseases of poverty: Epidemiology, infectious diseases, and modern plagues. Hanover, N.H: Dartmouth College Press. 
17. Newman, B. M., \& Newman, P. R. (2018). Development through life: A psychosocial approach.

18. Brown, J. L., \& Pollitt, E. (1996). Malnutrition, poverty and intellectual development, Sci Am 274(2):38-43. doi: 10.1038/ scientificamerican0296-38.

19. Chen, E., Matthews, K.A., \& Boyce, W.T. (2002). Socioeconomic differences in children's health: How and why do these relationships change with age? Psychological Bulletin, 128, 295-329.

20. Evans, G.W. (2004). The environment of childhood poverty. American Psychologist, 59, 77-92.

21. Hart, B., \&Risley, T. R. (1995). Meaningful differences: Everyday parenting and intellectual development in young American children. Baltimore, Md: Paul H. Brookes.

22. Evans, G. W. (2004). The Environment of Childhood Poverty. American Psychologist, 59, 2, 77-92.

23. Phillips, D., Voran, M., Kisker, E., Howes, C., \&Whitbook, M. (1994). Childcare for children in poverty: Opportunity or inequity? Child Development, 65, 472-492.

24. Miller, E.K. \& Cohen, J.D. (2001). An integrative theory prefrontal cortex function. Annual Review of Neuroscience, 24, 167-202.

25. Blair, C. (2006). How similar are fluid cognition and general intelligence? A developmental neuroscience perspective on fluid cognition as an aspect of human cognitive ability. Behavioral and Brain Sciences, 29, 109-125.

26. Vernon-Feagans, L., Cox, M. J., Conger, R., \& Society for Research in Child Development. (2013). The family life project: An epidemiological and developmental study of young children living in poor rural communities.

27. Bingenheimer, J.D., Brennan, R.T. \& Earls, F.J. (2005).Firearm violence exposure and serious violent behavior. Science, 308, 1323-1336.
28. Neild, R. C., Balfanz, R., Philadelphia Youth Network., Johns Hopkins University., \& University of Pennsylvania. (2006). Unfulfilled Promise: The Dimensions and Characteristics of Philadelphia's Dropout Crisis, 2000-2005.

29. Browning, C. R., Leventhal, T., \& Brooks-Gunn, J. (2005). Sexual Initiation in Early Adolescence: The Nexus of Parental and Community Control. American Sociological Review, 70, 5, 758-778.

30. Mollborn, S., \& Morningstar, E. (2009). Investigating the relationship between teenage childbearing and psychological distress using longitudinal evidence. Journal of Health and Social Behavior, 50, 3, 310-26.

31. Wickrama, K. A. S., Merten, M. J., \& Elder, J. G. H. (2005). Community influence on precocious transitions to adulthood: Racial differences and mental health consequences. Journal of Community Psychology, 33, 6, 639-653.

32. Wight, R. G., Aneshensel, C. S., Botticello, A. L., \&Sepúlveda, J. E. (2005). A multilevel analysis of ethnic variation in depressive symptoms among adolescents in the United States. Social Science \& Medicine, 60, 9, 2073-2084.

33. McBride Murry, V. V., Berkel, C., Gaylord-Harden, N. K., Copeland-Linder, N., \& Nation, M. (2011). Neighborhood Poverty and Adolescent Development. Journal Of Research On Adolescence (Wiley-Blackwell), 21(1), 114-128. doi:10.1111/ j.1532-7795.2010.00718.x

34. Durant, T., Mercy, J., Kresnow, M., Simon, T., Potter, L., \& Hammond, W. R. (2006). Racial Differences in Hopelessness as a Risk Factor for a Nearly Lethal Suicide Attempt. Journal of Black Psychology, 32, 3, 285-302.

35. Harrington, C.C. \& Boardman, S.K. (2000). Paths to success: Beating the odds in American society. Cambridge, MA: Harvard University Press. 